\title{
Review
}

\section{Nanoplastic Impact on the Gut-Brain Axis: Current Knowledge and Future Directions}

\author{
Wojciech Grodzicki ${ }^{1}\left(\mathbb{D}\right.$, Katarzyna Dziendzikowska $^{1, *(\mathbb{D}}$, Joanna Gromadzka-Ostrowska ${ }^{1}$ (D) \\ and Marcin Kruszewski ${ }^{2,3}$ (D)
}

1 Chair of Nutrition Physiology, Department of Dietetics, Institute of Human Nutrition Sciences, Warsaw University of Life Sciences, 02-787 Warsaw, Poland; wojciech_grodzicki@sggw.edu.pl (W.G.); joanna_gromadzka_ostrowska@sggw.edu.pl (J.G.-O.)

2 Centre for Radiobiology and Biological Dosimetry, Institute of Nuclear Chemistry and Technology, 03-195 Warsaw, Poland; m.kruszewski@ichtj.waw.pl

3 Department of Molecular Biology and Translational Research, Institute of Rural Health, 20-090 Lublin, Poland

* Correspondence: katarzyna_dziendzikowska@sggw.edu.pl

Citation: Grodzicki, W.; Dziendzikowska, K.; Gromadzka-Ostrowska, J.; Kruszewski, M. Nanoplastic Impact on the Gut-Brain Axis: Current Knowledge and Future Directions. Int. J. Mol. Sci. 2021, 22, 12795. https://doi.org/10.3390/ ijms222312795

Academic Editor: Valeria De Matteis, Mariafrancesca Cascione and Quaiser Saquib

Received: 28 October 2021

Accepted: 23 November 2021

Published: 26 November 2021

Publisher's Note: MDPI stays neutral with regard to jurisdictional claims in published maps and institutional affiliations.

Copyright: (c) 2021 by the authors. Licensee MDPI, Basel, Switzerland. This article is an open access article distributed under the terms and conditions of the Creative Commons Attribution (CC BY) license (https:// creativecommons.org/licenses/by/ $4.0 /)$.

\begin{abstract}
The widespread usage of plastic places a significant burden on the environment and impacts numerous aquatic and terrestrial species. Humans in particular can be affected by plastic pollution, predominantly via inhalation and ingestion, as well as trophic transfer along the food chain. Under natural conditions synthetic materials undergo degradation into micro- and nanoparticles, especially prone to interact with biological systems. Organisms exposed to nanoplastic accumulate it in multiple tissues, including the gut and the brain. This phenomenon raises a question about the impact of nanoparticulate plastics on the communication pathways between these organs. The aim of this review is to explore an unsettling possibility of the influence of nanoplastic on the gut-brain axis and provide a comprehensive summary of available data regarding this subject. The scarce but consistent evidence shows that exposure to plastic nanoparticles can indeed affect both the digestive and the nervous system. Reported outcomes include microbiota alterations, intestinal barrier permeability, oxidative stress, inflammation, neurotoxicity and behavioral disturbances. Taking into consideration these alarming observations and the ubiquitous presence of plastics in human environment, more research is urgently needed in order to identify any potential threats that nanoplastic exposure can pose to the functioning of the gut-brain axis.
\end{abstract}

Keywords: nanoplastic accumulation; inflammation; microbiome; intestinal barrier permeability; oxidative stress; neurotoxicity

\section{Introduction}

The current era of the Earth's history is frequently referred to as the Plasticene, the "Plastic Age". Although coined informally, the term seems to appropriately reflect the state of the global environment, ubiquitously polluted with synthetic plastic litter [1]. During the last decades plastic production worldwide has been steadily increasing, reaching 368 million tons in 2019 [2,3]. The total amount of plastic ever produced by humans has been estimated to be more than 8 billion tons. Approximately $60 \%$ of that amount was discarded as waste and accumulated in the environment [4]. This rejected, unrecycled material not only contaminates the land, but also ends up in the aquatic biome, forming plastic debris both on and beneath the water surface [2]. In fact, a calculation made in 2014 estimated that over five trillion plastic fragments float in seas and oceans around the world [5]. This enormous number becomes even more overwhelming taking into consideration the fact that a substantial part of the synthetic waste consists of particles in microscopic or smaller scale, more prone to interact directly with biological systems [2,5]. Due to physicochemical and biological processes, such as UV-induced decomposition and digestion by marine species, under environmental conditions plastic can undergo 
degradation into micro- (defined as smaller than $5 \mathrm{~mm}$ in diameter) and nanoparticles (defined as smaller than 1000 or $100 \mathrm{~nm}$ in diameter). Compared with larger fragments, these micro- and nanoplastics (MNPs) pose a less tangible, but not less dangerous threat to organisms. As it turns out, they can be harmful especially in regards to digestive and nervous systems of aquatic organisms and other elements of the food chain, probably also including humans $[2,6-8]$.

\section{Plastics in Human Environment}

Plastics are one of the materials most commonly used by humans, both in industry and everyday life. Their basic structure consists of repeated units forming polymers or copolymers that may be cross-linked or branched. Physicochemical properties of plastic depend on its chemical composition, especially on the inclusion of other chemical monomers that provide specific useful properties. The most prevalent types of plastic are polystyrene (PS), polyethylene (PE), polypropylene (PPL), polyvinyl chloride (PVC) and polyethylene terephthalate (PET). PS can be found in food containers and toys, PE in bin bags, shopping bags, bottle caps and bottles, PPL in straws and tubes, while PVC is commonly used in pipes or doors and PET is the main material in clothing fibers as well as containers for liquids and foods [9]. Plastics in the micro- and nanoparticulate form are pollutants that, like the original materials they come from, are chemically heterogeneous. Their chemical composition is very diverse, with the vast majority being PPL, PE and PS, followed by nylon, polyester and acrylic fibers. Statistically, polyurethane microparticles are the least common type of MNPs [10].

Plastic pollution, including MNPs, affects multiple environmental compartments. Given the fact that synthetic materials, by definition, are of human origin, the contamination starts on land through waste generation $[9,11]$. Marine ecosystems are particularly vulnerable to the negative impact of MNPs, as nearly $10 \%$ of the plastic produced annually is transported to seas and oceans, mostly via rivers. Moreover, especially small particles can also be easily spread by wind, making atmospheric air an important vehicle for MNPs distribution [9,12]. Different contamination sources raise questions about human exposure routes. Plastic can enter the body through three major pathways: by skin contact, inhalation and oral ingestion [13]. Dermal exposure results primarily from the use of hygiene products and clothing. Although this route is probably not a significant source of MNPs, since they do not penetrate deeply into skin layers, the available data are still not conclusive [13-15]. Regarding the exposure via respiratory tract, analyses of the atmospheric fallout and direct measurements of suspended particulate matter from different sources confirmed the presence of synthetic materials in the air [16-18]. Notably, concentrations of plastics are greater in suburban than urban areas and indoors compared to outdoors [16,17]. The total daily exposure calculated by Prata is estimated to fall within the range of 26 to 130 plastic microparticles/day and could be of physiological relevance [18].

In light of the existing data it seems that the main route of MNPs' entry into the human body may be the gastrointestinal tract (GI tract). Therefore, special attention has been paid to the oral intake of MNPs, which seems to reach potentially harmful levels [19-21]. In a recent systematic review and meta-analysis Danopoulos et al. stated that the primary source of plastics in the human diet is seafood, which is not surprising, given the widespread contamination of aquatic environments [20]. In another review, Toussaint et al. found that up to 200 edible marine species can be affected by MNPs pollution, among which the content of plastic particles in sardines and sprats is especially well-documented [22]. Danopoulos et al. indicated that human exposure rate to MNPs could vary considerably depending on the geographic region, which determines to a substantial extent seafood consumption level. Based on the data available from the Food and Agriculture Organization of the United Nations (FAO), the authors calculated that the annual MNPs intake originated from different marine species combined could reach almost 54,000 particles per person, which equals 147.9 particles/person/day [20]. 
Although less evident, foodstuffs other than seafood can also contribute to MNPs oral exposure. Microscopic plastics have been found in honey, sugar and salt samples, the total content ranging from less than 10 to several hundred pieces $/ \mathrm{kg}$. Analyses of different beverages yielded similar results, beer being the least and bottled drinking water the most contaminated with particulate plastic [11,22]. A 2019 study by Hernandez et al. suggests that the list of relevant food sources of MNPs should also include tea. An experiment carried out on plastic teabags showed that under standard brewing conditions one cup of such a beverage could contain up to 2.3 million of microplastic particles (MPs) and 14.7 billion of nanoplastic particles (NPs). Therefore, only two cups of tea per day would expose the drinker to 29.4 billion MNPs, which far exceeds the amounts reported for any other food [19]. Moreover, some authors hypothesized that the aforementioned indoor air pollution could contribute to the oral exposure through dust settling on plates during meal preparation, making sensible estimations even more complicated. In fact, up to $68,415 \mathrm{MPs}$ annually or 187.4 MPs daily could enter the human body this way [23]. According to Cox et al. the total microplastic consumption in the American population, inhalation and oral exposure combined, could surpass 121,000 particles/person/year. Drinking water alone, assuming only bottled one was consumed, could contribute to the ingestion of 90,000 MPs every year (or 246.6 MPs every day). Nevertheless, as emphasized by the authors, those values represent only a rough approximation and the real amounts might be higher [24]. As far as the actual mass of MNPs ingested by humans is concerned, Senathirajah et al. determined it to fall within the range of 0.1 to even $5 \mathrm{~g} /$ person/week. The authors based their estimations on an average mass of an individual plastic particle derived from different studies and took into consideration oral intake from shellfish, salt, beer and drinking water [25]. As a simple calculation shows, assuming a typical body weight of $70 \mathrm{~kg}$, the level of exposure they reported translates into $0.2-10.2 \mathrm{mg} / \mathrm{kg} \mathrm{bw} /$ day, which equals dosages used in studies of plastic toxicity [7]. Although staggering, this global average still does not reflect a whole picture, since it excludes many potential sources, such as inhalation route, and does not account neither for individual variability between consumers nor for different plastic characteristics [25]. Approximated levels of human plastic exposure from selected sources are summarized in Figure 1.

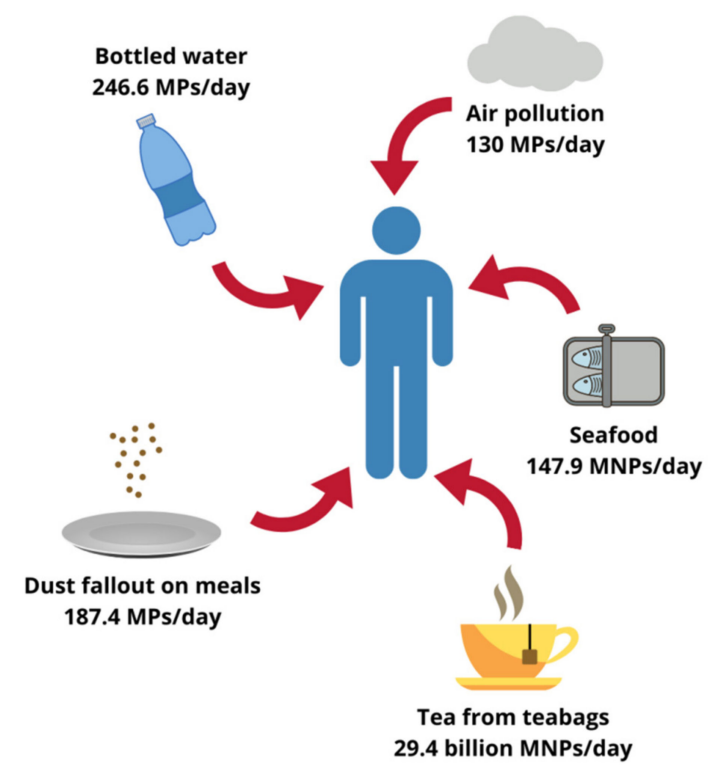

Figure 1. Possible human exposure level to plastics originating from different sources. MPs, microplastic particles; MNPs, micro- and nanoplastic particles. Designed using elements by @Canva, sparklestroke, Pixeden, iconsy, OpenClipart-Vectors via Canva.com ( access date: 18 November 2021, version used Canva 2.0). 


\section{Toxic Potential of Plastic Particles}

The toxic potential of MNPs is an open question. The literature published so far suggests that any severe, acute outcomes related to plastic exposure in humans are not likely. However, little is known about long-lasting, more subtle effects [8]. An important hint is the finding that MNPs are able to accumulate in different tissues. Studies on marine species showed that after exposure plastic particles were detected not only in the digestive tract and gills, the main routes of entry to the organism, but also in blood, liver, pancreas, heart and, notably, in the brain $[7,8]$. MNPs presence in biological compartments was associated with adverse effects, such as intestinal damage, shifts in microbiota composition, increased oxidative stress, inflammation, neuronal dysfunction and abnormal behavior $[7,8,15]$.

Although much more scarce, experiments concerning mammalian models yield comparable outcomes. A recent review by Yong et al. identified four studies on rodents reporting MNPs accumulation. Following exposure, multiple pathological processes were observed, including gut dysbiosis, intestinal barrier dysfunction, changes in metabolism, increased oxidative stress and signs of neurotoxicity [8]. Additionally, in vitro experiments on various human cell lines showed that MNPs elicited oxidative stress, inflammatory response and cytotoxicity $[8,15]$. The literature directly related to human subjects is almost non-existing. Schwabl et al. detected MPs in stool of adult volunteers, suggesting MNPs impact on the digestive tract, whereas Ragusa et al. reported the presence of plastic particles in maternal placenta [26,27]. Taken together, the available data provide evidence for toxic potential of plastic particles, especially in the nanoscale [15]. Of note, their harmful effects are more pronounced in the digestive system, which is expected to be the major route of exposure. Moreover, a disturbing pattern of neurotoxicity emerges consistently as a severe side effect of NPs exposure among experiments conducted both in vitro and in vivo.

\section{The Gut-Brain Axis}

The GI tract and the central nervous system (CNS) are connected by a complex network of mutual interactions, known as the gut-brain axis (GB axis) [28]. The fact that the GI tract not only serves the role of digesting and absorbing nutrients, but also constitutes one of the main areas of contact between the organism and its external environment, makes it at the same time essential for survival and vulnerable to potential threats from outside the body. From this point of view it is logical that the alimentary canal is closely tied to the brain, the master controller of most physiological functions [29,30]. Noteworthy, an increasing body of evidence points towards an important role of microbiota in the bidirectional interplay between the gut and the brain [31-33].

The core of the GB axis consists of the vagus nerve, the $\mathrm{X}$ cranial nerve and simultaneously a branch of the autonomic nervous system (ANS). It sends information about the state of the inner organs, via afferent fibers, to the brain and connects the CNS to the enteric nervous system (ENS). The vagus nerve is sensible to diverse stimuli, including mechanical tension, hormones and other chemical incentives, that elicit a wide array of effects in the brain, stimulating regions related to feeding behavior, anxiety or emotions $[28,31,33]$. On the other hand, efferent vagal activity has an impact on the gut environment, influencing the immune system and metabolism [31,33]. Simultaneously, the CNS interacts with the GI tract via the hypothalamic-pituitary-adrenal axis (HPA axis), also integrated into the gut-brain communication pathways [31]. In response to stressors the hypothalamus releases corticoliberin, which stimulates the pituitary gland to produce adrenocorticotropin (ACTH). Subsequently, the ACTH acts on the adrenal glands, inducing the synthesis of cortisol (or corticosterone in rodents), the main stress hormone, able to modulate diverse gastrointestinal processes [28].

Direct effects of diverse neuronal and hormonal stimulation on the GI tract are possible due to the ENS, an intricate complex of nerves situated beneath the intestinal mucosa [31,33]. ENS is highly sensitive to different stimuli from the intestinal lumen and, given its connection to the vagus nerve, plays an important role in the communication 
of the GI tract with the CNS, sometimes being even referred to as the body's "second brain" $[28,31,33]$. The plexuses of the ENS are located in close vicinity to the epithelium, which creates a tight barrier between the gut lumen and underlying tissues, preventing the unwanted passage of food and microbial antigens deep into the mucosa. A disruption of the barrier has been observed in several psychiatric disorders, including anxiety and depression, which suggests a link between gut permeability and CNS function $[29,33]$. Moreover, the intestinal barrier can be influenced by the HPA axis through cortisol activity and, on the other hand, by the gut microbiota. Microorganisms residing in the GI tract promote production of protective mucus and short-chain fatty acids (SCFA), which restore the intestinal epithelial cells and also the integrity of tight junctions [28,31,33]. Besides the physical defense provided by the intestinal barrier, the digestive tract is protected against multiple environmental factors by immune cells in the gut-associated lymphoid tissue (GALT) $[29,31,34]$. Specialized GALT components, namely $M$ cells and dendritic cells, interact with antigens present in the lumen and stimulate the underlying $\mathrm{T}$ and $\mathrm{B}$ cells, situated in Peyer's patches, to release cytokines. Those, in turn, induce immune response, which can propagate further outside the GI tract, reach the CNS via bloodstream and influence the vagus nerve signaling $[29,31]$.

GALT contains the highest concentration of immune cells in the entire human organism and provides the primary space of exposure to microbial agents and their metabolites [31,34]. The totality of these microorganisms is known as the gut microbiota and, as a growing body of evidence demonstrates, heavily affects CNS functioning, blood-brain barrier (BBB) permeability, brain cells development and neuron maturation [31,32,34,35]. Additionally, microbial metabolites, such as tryptophan precursors, serotonin or catecholamines, act as neuromodulators, while SCFA produced by gut bacteria might stimulate the vagus nerve, affect neurotransmitter metabolism and have an impact on behavior [31]. Moreover, changes in microbiota have been linked to the development of different CNSrelated disorders, including pathogeneses of Alzheimer's disease, Parkinson's disease, autism and depression [33].

Taken together, there are multifarious ways of communication between the gut and the brain. They entail diverse systems, such as the ANS, HPA axis, ENS, intestinal barrier, GALT and the microbiota, which maintain a constant dialogue and exchange information across different pathways encompassed by the GB axis [28]. Given the crucial physiological function of the axis and its involvement in numerous neurological disorders, any potential disrupting agents should be closely investigated. Therefore, the scarce but consistent evidence linking NPs exposure to both gut and brain alterations should be a cause of particular concern and requires thorough analysis.

\section{Impact of Nanoplastic Exposure on the Gut-Brain Axis}

Data regarding NPs and their impact on living organisms indicate that the main risk associated with plastic exposure is a non-acute toxicity, particularly with respect to the digestive and the nervous system $[7,8]$. The vulnerability of the GI tract can be explained by the fact that it constitutes one of the principal routes of entry for NPs into the organism and is subjected to a relatively high plastic load $[19,24,36]$. In regards to the CNS-related structures, there is a parallelism between the effects provoked by NPs and other nanoparticles. Many nanomaterials, especially metallic nanoparticles, have well-documented neurotoxic properties [37,38]. Moreover, evidence from human studies shows that nanoparticulate pollutants, such as combustion-derived nanoparticles, are able to accumulate in the vagus nerve, the core of the GB axis, and contribute to neurodegeneration [39]. Therefore, NPs of similar size can be expected to produce analogous outcome. Although, to the best of our knowledge, there are no studies directly focused on the impact of NPs on the GB axis, the available data provide hints about possible consequences of plastic exposure for the communication pathway connecting the GI tract and the brain. The following is the description of experimental studies investigating NPs-related toxicity in regards to several elements of the GB axis. 


\subsection{In Vitro Studies on Cellular Cultures}

Preliminary findings from several in vitro experiments yield noteworthy results regarding NPs impact on different cell lines originating from the GI tract and the CNS. Busch et al. investigated the effects of $59 \mathrm{~nm}$ pristine polystyrene (PS) particles, $59 \mathrm{~nm}$ amino-modified PS NPs or $279 \mathrm{~nm}$ PVC NPs $(1-50 \mu \mathrm{g} / \mathrm{mL}, 24 \mathrm{~h})$ in a cellular model of healthy and inflamed human intestine using epithelial (Caco2 and HT29-MTX-E12) and immune cells (THP1 macrophages). The treatment of monocultures with amino-modified PS NPs caused a dose-dependent reduction of metabolic activity, inflammatory response evidenced by an increased release of interleukin $1 \beta$ (IL-1 $\beta$ ) and DNA damage. None of these were present if pristine PS or PVC NPs were applied. In the triple culture models, in healthy cells treated with modified PS the authors reported increased cytotoxicity and decreased expression of tight junction protein 1, suggesting compromised intestinal barrier integrity. They also observed a dose-dependent loss of nuclei in the epithelial layer in the inflammation model treated with PVC, but not with modified or non-modified PS. The most pronounced effects were found for amino-modified PS NPs, known to destabilize cell membranes and disintegrate lysosomes upon intracellular uptake. However, these data are not relevant to the environmental exposure, since these NPs are used only in experimental conditions. Nevertheless, the slight toxicity induced by PVC NPs means that they could potentially aggravate an already existing inflammatory state [40].

In a similar experiment Domenech et al. studied the effects of PS nanoplastic $(5-100 \mathrm{~nm}$, 1-100 $\mathrm{\mu g} / \mathrm{mL}$ ) exposure on human intestinal barrier models (Caco-2/HT29 and Caco$2 /$ HT29 + Raji-B cells). In line with previous results no significant changes in the expression of oxidative stress-related genes and no signs of toxicity were observed after $24 \mathrm{~h}$ of treatment [41]. Hesler et al. also did not report cytotoxicity of COOH-modified PS NPs $(50 \mathrm{~nm}$ or $500 \mathrm{~nm})$, applied for $24 \mathrm{~h}(0.1-100 \mu \mathrm{g} / \mathrm{mL})$ to an intestinal Caco-2/HT29-MTXE12 co-culture model of the intestine, despite a marked PS NPs uptake by intestinal cells. The authors hypothesized that this intracellular accumulation could result in long-term toxicity and distribution to other tissues [42]. Indeed, translocation of NPs was reported by Walczak et al., who compared differently charged non-digested and artificially pre-digested PS NPs ( $50 \mathrm{~nm}, 250 \mu \mathrm{g} / \mathrm{mL}, 24 \mathrm{~h}$ ) in the same co-culture intestinal model. Interestingly, pre-digestion process significantly increased NPs translocation through intestinal cell layer, which is highly relevant for real-life conditions of oral plastic exposure. Moreover, positively charged pre-digested NPs provoked a decrease of intestinal barrier integrity, measured by transepithelial electrical resistance, and increased its permeability [43].

NPs have also been studied in regards to their impact on brain cells. Jung et al. treated different murine cells with $100 \mathrm{~nm}$ PS NPs and observed intracellular deposition of NPs in astrocytes as well as in mixed neuronal culture, especially in cell bodies of neurons close to the nuclei. Neuronal cells were also affected in terms of viability, which was significantly reduced due to the NPs treatment. Nanoplastic also influenced neuronal development, as shown by alterations in the expression of genes involved in the process, namely Tubb3 and Gfap. In addition, in astrocytes PS NPs increased proinflammatory signaling, including up-regulation of the tumor necrosis factor alpha (TNF- $\alpha$ ) gene (Tnfa) and IL-1 $\beta$ (Illb). Although the viability of astrocytes was not affected by PS NPs, the authors speculated that the exposure might have induced reactive astrocytosis, leading to inflammation and death of nearby neurons [44]. Signs of neurotoxicity were also reported by Schirinzi et al., who explored cellular effects caused by different kinds of MNPs, including PE micro$(3-16 \mu \mathrm{m})$ and nanoparticles $(100-600 \mathrm{~nm})$ as well as PS micro- $(10 \mu \mathrm{m})$ and nanoparticles (40-250 nm). Treatment of human glioblastoma T98G cells with plastics for $24 \mathrm{~h}$ resulted in an increased generation of reactive oxygen species (ROS), the effects being more noticeable for PS [45].

In another study Murali et al. sought to investigate in vitro reactivity of "fresh" or "aged" PS NPs (45-70 nm) with distinct surface modifications and in conjunction with microbial toxins. In the case of "fresh" NPs the authors did not observed any uptake of NPs by neurons or astrocytes, however, intracellular accumulation occurred in microglia 
exposed to carboxylated particles. These NPs were found to be severely toxic at the highest concentrations, in contrast to the ones coated with polyethylene glycol that turned out to be harmless. Interestingly, assays involving NPs after 6 months storage brought very different results. The process of ageing not only enhanced the cellular uptake of NPs, possibly through the endocytotic pathway, but also increased their cytotoxicity in NE4C neuronal stem cells and microglia. Furthermore, the authors observed that bacterial lipopolysaccharide (LPS) was easily adsorbed by NPs and promoted their uptake by microglia cells, which could lead to increased cytotoxicity [46]. These important findings show that, while non-modified plastic nanoparticles may be relatively innocuous, changes they likely undergo in the environment can significantly alter their properties.

Results confirming nanoplastic neurotoxicity in vitro were also described by Hoelting et al., who employed an embryonic stem cell (hESC)-derived 3-dimensional model of human neural development exposed to $33 \mathrm{~nm}$ PE NPs in a short- and a long-term fashion. In the short term $(48 \mathrm{~h})$ the majority of neurospheres internalized NPs only when exposed to the highest concentration that resulted in cytotoxicity and oxidative stress, evidenced by an increase of malondialdehyde. After 18 days of treatment, however, accumulation of nanoplastic was detectable even at low concentrations. Although non-toxic, low concentration down-regulated genes related to neurodevelopment, such as HES5, NOTCH1, FOXG1, NEUROD1 and ASCL1. The authors concluded that their findings highlight the possibility of NPs-induced developmental neurotoxicity [47].

Currently, in vitro research exploring the toxicity of NPs with regards to the GI tract and CNS cells is still scarce. In addition, in the limited number of existing studies different types, sizes and concentrations of nanoplastics have been used, which complicates direct comparisons. Nevertheless, those preliminary findings share certain commonalities, allowing for some generalization. NPs seem to be able to penetrate gut cells, creating an opportunity for further distribution. In brain cells models nanoplastic is internalized, elicits oxidative stress and reduces cell viability, particularly in the more realistic, "aged" form. The summary of these research is presented in Table 1.

Table 1. In vitro NPs toxicity related to the GB axis.

\begin{tabular}{|c|c|c|c|c|}
\hline Cell Models & NPs Type and Size & Exposure & $\begin{array}{l}\text { Effects Related to the GB } \\
\text { Axis }\end{array}$ & Reference \\
\hline $\begin{array}{c}\text { Human intestinal } \\
\text { Caco-2, HT29-MTX-E12 and THP-1 monocul } \\
\text { tures; triple culture human intestinal } \\
\text { Caco-2/HT29-MTX-E12/THP-1 model(healthy } \\
\text { or inflamed) }\end{array}$ & $\begin{array}{l}\text { Pristine/amino-modified } \\
\text { PS NPs }(59 \mathrm{~nm}) \\
\text { PVC NPs }(279 \mathrm{~nm})\end{array}$ & $\begin{array}{c}24 \mathrm{~h} \\
(1-50 \mu \mathrm{g} / \mathrm{mL})\end{array}$ & $\begin{array}{c}\text { Monocultures/amino- } \\
\text { modified PS: } \\
\text { metabolic disruption, } \\
\text { inflammation, DNA damage; } \\
\text { healthy triple culture } \\
\text { model/amino-modified PS: } \\
\text { increased cytotoxicity, } \\
\text { decrease of tight junction } \\
\text { protein } 1 \text {; inflamed triple } \\
\text { culture model/PVC: } \\
\text { loss of nuclei }\end{array}$ & [40] \\
\hline $\begin{array}{c}\text { Human intestinal } \\
\text { Caco-2/HT29 and Caco-2/HT29 + Raji-B cells }\end{array}$ & PS NPs (5-100 nm) & $\begin{array}{c}24 \mathrm{~h} \\
(1-100 \mu \mathrm{g} / \mathrm{mL})\end{array}$ & No significant toxic effects & [41] \\
\hline $\begin{array}{c}\text { Human intestinal } \\
\text { Caco-2/HT29-MTX-E12co-culture model }\end{array}$ & $\begin{array}{l}\text { Carboxylated PS NPs } \\
\quad(50 \text { and } 500 \mathrm{~nm})\end{array}$ & $\begin{array}{c}24 \mathrm{~h} \\
(0.1-100 \mu \mathrm{g} / \mathrm{mL})\end{array}$ & Uptake of NPs & [42] \\
\hline $\begin{array}{l}\text { Human intestinal } \\
\text { Caco-2/HT29-MTX } \\
\text { co-culture model }\end{array}$ & $\begin{array}{l}\text { Pristine/positively/negatively } \\
\text { charged } \\
\text { PS NPs }(50 \mathrm{~nm}) \\
\text { non-digestedor digested } \\
\text { in vitro }\end{array}$ & $\begin{array}{c}24 \mathrm{~h} \\
(250 \mu \mathrm{g} / \mathrm{mL})\end{array}$ & $\begin{array}{l}\text { Digested NPs: enhanced } \\
\text { translocation across cells; } \\
\text { positively charged NPs: } \\
\text { increased intestinal barrier } \\
\text { permeability }\end{array}$ & [43] \\
\hline Murine mixed neuronal cells; primary astrocytes & PS NPs (100 nm) & $\begin{array}{c}48 \mathrm{~h} \\
(50-200 \mu \mathrm{g} / \mathrm{mL})\end{array}$ & $\begin{array}{l}\text { Uptake of NPs; mixed } \\
\text { neuronal cells: reduced cell } \\
\text { viability, altered expression of } \\
\text { Tubb3 and Gfap; primary } \\
\text { astrocytes: increased } \\
\text { expression of Tnfa and } I l 1 b\end{array}$ & [44] \\
\hline
\end{tabular}


Table 1. Cont.

\begin{tabular}{|c|c|c|c|c|}
\hline Cell Models & NPs Type and Size & Exposure & $\begin{array}{c}\text { Effects Related to the GB } \\
\text { Axis }\end{array}$ & Reference \\
\hline $\begin{array}{l}\text { Human neuronal } \\
\text { T98G cells }\end{array}$ & $\begin{array}{l}\text { PE NPs }(100-600 \mathrm{~nm}) \\
\text { PS NPs }(40-250 \mathrm{~nm})\end{array}$ & $\begin{array}{c}24 \mathrm{~h} \\
(0.05-10 \mu \mathrm{g} / \mathrm{mL})\end{array}$ & Increased ROS generation & [45] \\
\hline $\begin{array}{c}\text { Murine NE-4C } \\
\text { Neuroectodermal stem cells; neuron-enriched } \\
\text { primary brain cell cultures; primary astrocytes; } \\
\text { microglial cultures; brain vascular endothelial cell } \\
\text { cultures }\end{array}$ & $\begin{array}{l}\text { Carboxylated/PEGylated PS } \\
\text { NPs ( } 45-70 \text { nm), "fresh" or } \\
\text { “aged"( } 6 \text { months < of storage })\end{array}$ & $\begin{array}{c}1 \mathrm{~h} \\
(50 \mu \mathrm{g} / \mathrm{mL}) \\
24 \mathrm{~h} \\
(7.8-250 \mu \mathrm{g} / \mathrm{mL})\end{array}$ & $\begin{array}{l}\text { "Fresh" carboxylated NPs: } \\
\text { uptake by microglia; "aged" } \\
\text { NPs: uptake and cytotoxicity } \\
\text { in NE-4C neuronal stem cells } \\
\text { and microglia; enhanced } \\
\text { cellular uptake of NPs caused } \\
\text { by LPS adsorption }\end{array}$ & [46] \\
\hline $\begin{array}{l}\text { Embryonic stem cell (hESC)-derived 3-dimensional } \\
\text { model of human neural development }\end{array}$ & PE NPs (33 nm) & $\begin{array}{c}48 \mathrm{~h} \\
(5.6-1440 \mu \mathrm{g} / \mathrm{mL}) \\
18 \text { days } \\
(5.6-360 \mu \mathrm{g} / \mathrm{mL})\end{array}$ & $\begin{array}{l}\text { Uptake of NPs; reduced cell } \\
\text { viability; oxidative stress; } \\
\text { down-regulation of HES5, } \\
\text { NOTCH1, FOXG1, NEUROD1 } \\
\text { and ASCL1 }\end{array}$ & [47] \\
\hline
\end{tabular}

\subsection{In Vivo Studies on Fish}

A relatively high number of studies have investigated the impact of MNPs on marine organisms, perhaps the most striking being the one describing a recently discovered new crustacean species, Eurythenes plasticus, whose name refers to the plastic microfiber found within the animal's alimentary canal [48]. Nonetheless, in regards to the NPs-induced effects relevant to the GB axis, published articles regarding in vivo experiments on aquatic vertebrates species are not abundant. Veneman et al. studied NPs impact on transcriptomic responses in zebrafish larvae (Danio rerio). $700 \mathrm{~nm}$ PS NPs $(5 \mathrm{mg} / \mathrm{mL}$ ) were injected into 2-day old embryos resulting in multiple changes in gene expression, though NPs did not penetrate beyond the vascular system. The exposed larvae showed alterations in the expression of 26 genes 1-day post-injection and 51 genes 3 days after the treatment, showing signs of complement system stimulation as well as activation of pathways related to toxicity and oxidative stress [49].

Similarly, changes in ROS and antioxidant parameters were observed upon exposure to PS nano- $(50 \mathrm{~nm})$ and microparticles $(45 \mu \mathrm{m})$ of Marine medaka (Oryzias melastigma). Histological analysis showed that nanoplastic particles accumulated within and around digestive organs. Moreover, nanoplastic, but not microplastic, increased the activity of antioxidant enzymes, superoxide dismutase (SOD) and catalase (CAT), in the gut and induced apoptosis detected as DNA breaks. However, microparticulate PS affected microbiota composition more significantly than nanoparticulate PS, mainly by decreasing the abundance of Bacteroidetes [50]. These results indicate that the effects provoked by MNPs are size-specific and that NPs may be more prone to disturb the redox balance, while MPs cause a more pronounced dysbiosis.

Fish vulnerability to NPs was also studied by Kashiwada, who exposed adult Japanese medaka (Oryzias latipes) to $39.4 \mathrm{~nm}$ PS NPs, which resulted in a significant accumulation of NPs in the intestine as well as in the brain, indicating their ability to cross the BBB. Unfortunately, no further assays were performed, apart from the distribution patterns, making it impossible to draw conclusions regarding any potential neurotoxic effects [51]. In line with these results, accumulation of PS NPs $(51 \mathrm{~nm})$ was detected by Pitt et al. in the GI tract and head of Danio rerio embryos treated from 6 to $120 \mathrm{~h}$ post-fertilization. Although no acute toxicity was observed, behavioral tests revealed reduction of larval locomotor activity, suggesting NPs deposition in the brain. These findings indirectly confirm the harmful effect NPs could have had on the developing CNS [52].

An interesting approach to the NPs toxicity involving the food chain effects was described by Chae et al., who studied the trophic transport and toxicity of $51 \mathrm{~nm}$ PS NPs on four different marine species. First, green algae (Chlamydomonas reinhardtii) were exposed to NPs for $72 \mathrm{~h}$, then the algae were given to planktonic neonates (Daphnia magna) for $5 \mathrm{~h}$, which in turn served as feed for Chinese medaka (Oryzias sinensis) for $48 \mathrm{~h}$. Finally, O. sinensis were given to a predator fish, dark chub (Zacco temminckii) for $24 \mathrm{~h}$. Screening for NPs accumulation performed after the food chain-mimicking procedure revealed 
penetration of PS NPs into the algae cells and their presence in the gut of D. magna. The accumulation of PS was accompanied by histological changes visualized as damage to the intestinal wall. In final consumers nanoplastic was detected in the gut of $O$. sinensis and in both the gut and the stomach of Z. temminckii. Thus, the trophic transfer potential of NPs in the aquatic environment was confirmed. Furthermore, every species was exposed to NPs individually to evaluate the toxicity separately. No significant effects were reported neither for C. reinhardtii after treatment for $72 \mathrm{~h}$ nor for D. magna exposed for $48 \mathrm{~h}$. However, harmful impact of nanoscale plastic became more evident in the vertebrates undergoing a 7-day treatment. Both O. sinensis and Z. temminckii showed disturbed locomotive activities, manifested as abnormal swimming patterns. These behavioral changes, as the authors hypothesized, could have been related to brain damage caused by the exposure [53].

Another study involving trophic transfer of NPs in aquatic environment was conducted by Mattsson et al., who investigated the effects of sulfonated 24 and $27 \mathrm{~nm}$ PS NPs delivered through a 3-level food chain to the Crucian carp (Carassius carassius). First, nanoplastic was given to algae (Scenedesmus sp.), which were later eaten by zooplankton (D. magna). Finally, the contaminated D. magna served as food for the carps. Behavioral tests conducted after 61 days of treatment showed slower movement, less exploration activity and diminished hunting performance in carps receiving nanoparticles compared to the control group. Moreover, histological analysis revealed changes in color, texture and water content of brains sampled from exposed fish, suggesting an impact of NPs. The authors explained these findings by the affinity of PS to lipid molecules, resulting in a possible accumulation in fat-rich organs, such as the brain [54]. These results were later corroborated by the same authors, who in a similar experiment investigated the effects of $180 \mathrm{~nm}$ and $53 \mathrm{~nm}$ amino-modified PS delivered to fish through an analogous food chain. As observations revealed, carps exposed to $53 \mathrm{~nm}$ NPs ate more slowly and swam longer before reaching the prey. These effects, affecting feeding efficiency and potentially undermining environmental survival, were linked to alterations in the brain. Cerebral tissue of exposed fish not only accumulated nanoplastic, but also contained less water and underwent morphological changes in the gyri of cerebral lobes [55].

A deeper insight into neurotoxic mechanisms of NPs was provided in the study by Chen et al., who examined the influence of PS MPs $(45 \mu \mathrm{m})$ and NPs $(50 \mathrm{~nm})$ on zebrafish larvae behavior, gene expression and enzymatic activity. Treatment with both types of particles resulted in size-dependent alterations in exposed embryos. Whereas swimming distance in darkness was not altered by MPs, treatment with NPs reduced it notably. Principal component analysis showed that these behavioral alterations were accompanied by changes in antioxidant biomarkers, among which reduced glutathione (GSH) level was significantly lowered in comparison with the control group. Exposure to nanoplastic also affected body length, which was found to be decreased in exposed larvae. In addition, two genes involved in neurodevelopment, namely Gfap and $\alpha 1$-tubulin, were up-regulated only in the NPs group. Finally, the activity of acetylcholinesterase (AChE), a key enzyme involved in neurotransmission, was significantly decreased due to the NPs, but not the MPs treatment [56].

Similarly unsettling outcomes were reported by Sarasamma et al. in an in vivo study on adult zebrafish treated with $70 \mathrm{~nm}$ PS NPs in acute (7 days) or chronic (30 days or 7 weeks) regimes. Histological analysis after the 30-day exposure period revealed that plastic particles were present in multiple tissues, including the intestine and the brain. Moreover, detailed analyses of brain tissues sampled after the 7-day experiment showed a decrease in numerous neurotransmitter and hormone levels. Alterations included lowered AChE, dopamine, melatonin, $\gamma$-aminobutyric acid, 5-hydroxytryptophan, vasopressin, kisspeptin and oxytocin. In terms of behavior, 7-week exposure to NPs led to circadian dysregulation in terms of locomotive activity, including a reduction in average speed and rapid movement time ratio during the light cycle as well as hypoactivity during the dark cycle. The 7-day treatment resulted in exploratory hyperactivity, reduced aggressiveness, worsened predator avoidance and altered shoaling. Notably, disturbances in most of 
the behavioral endpoints measured were more pronounced in the group exposed to the higher concentration of NPs [57]. This thorough behavioral assessment, together with the confirmation of tissue distribution and changes in the CNS, provide a strong evidence for NPs-induced neurotoxicity and highlight the importance of plastic load, with higher concentrations being significantly more harmful.

Data regarding NPs impact on GB axis derived from in vivo studies on aquatic vertebrates are still insufficient to draw definitive conclusions. Furthermore, the size and concentration of particles applied are often too dissimilar to confidently compare results derived from different experiments. However, studies conducted up to date are consistent in at least several aspects. They clearly show size-dependent differences in toxicity, NPs being more harmful than MPs, possibly due to their smaller diameter and, consequently, higher bioactivity. There is also convincing preliminary evidence for translocation of NPs from the gut to the brain and their ability to cross the BBB. In conjunction with behavioral alterations, possible neurodevelopmental disturbances, impact on enzymatic activity, induction of oxidative stress and immune system activation, the influence of nanoplastic on the GB axis becomes a plausible phenomenon. The summary of these research is presented in Table 2.

Table 2. Summarized data derived from in vivo experiments on fish regarding toxic effects of NPs related to the GB axis.

\begin{tabular}{|c|c|c|c|c|}
\hline Fish & NPs Type and Size & Exposure & Effects Related to the GB Axis & Reference \\
\hline Zebrafish (D. rerio) & PS NPs $(700 \mathrm{~nm})$ & Single-dose injection $(5 \mathrm{mg} / \mathrm{mL})$ & $\begin{array}{l}\text { Altered expression of } 26 \text { genes } 1 \text { day } \\
\text { and } 51 \text { genes } 3 \text { days post-injection; } \\
\text { activation of the complement system; } \\
\text { activation of oxidative } \\
\text { stress-related pathways }\end{array}$ & [49] \\
\hline Marine medaka (O. melastigma) & PS NPs (50 nm) & $\begin{array}{c}\text { In water for } 24 \mathrm{~h}(10 \mu \mathrm{g} / \mathrm{mL}) \text { or } \\
14 \text { days }(2.5 \mu \mathrm{g} / \mathrm{mL})\end{array}$ & $\begin{array}{c}\text { NPs accumulation in the digestive } \\
\text { system; induction of apoptosis in the } \\
\text { gut; increased activity of SOD and CAT } \\
\text { in the gut }\end{array}$ & [50] \\
\hline Japanese medaka (O. latipes) & PS NPs $(39.4 \mathrm{~nm})$ & In water for 7 days $(10 \mu \mathrm{g} / \mathrm{mL})$ & NPs accumulation in the gut and brain & [51] \\
\hline Zebrafish (D. rerio) & PS NPs (51 nm) & In water for $114 \mathrm{~h}(0.1-10 \mu \mathrm{g} / \mathrm{mL})$ & $\begin{array}{l}\text { NPs accumulation in the gut and head; } \\
\text { behavioral alterations }\end{array}$ & [52] \\
\hline $\begin{array}{l}\text { Chinese medaka (O. sinensis) } \\
\text { Dark chub (Z. temminckii) }\end{array}$ & PS NPs (51 nm) & $\begin{array}{c}\text { In water for } 7 \text { days }(5 \mu \mathrm{g} / \mathrm{mL} \text {, } \\
\text { individual toxicity) } \\
\text { For } 48 \mathrm{~h}(\text { O. sinensis }) \text { or } 24 \mathrm{~h} \\
\text { (Z. temminckii) via trophic transfer } \\
\text { (C. reinhardtii } \rightarrow \text { D. magna } \rightarrow \text { O. sinensis } \\
\rightarrow \text { Z. temminckii) }\end{array}$ & $\begin{array}{l}\text { Individual toxicity: behavioral } \\
\text { alterations; } O \text {. sinensis / trophic transfer: } \\
\text { NPs accumulation in the gut; } \\
\text { Z. temminckii/trophic transfer: NPs } \\
\text { accumulation in the gut and stomach }\end{array}$ & [53] \\
\hline Crucian carp (C. carassius) & $\begin{array}{l}\text { Sulfonated PS NPs } \\
\quad(24 \text { and } 27 \mathrm{~nm})\end{array}$ & $\begin{array}{c}\text { For } 61 \text { days via trophic } \\
\text { transfer(Scenedesmus sp. } \rightarrow \text { D. magna } \\
\rightarrow \text { C. carassius })\end{array}$ & $\begin{array}{l}\text { Histological changes in the brain; } \\
\text { behavioral alterations }\end{array}$ & [54] \\
\hline Crucian carp (C. carassius) & $\begin{array}{l}\text { Amino-modified } \\
\text { PS NPs } \\
(53 \text { and } 180 \mathrm{~nm})\end{array}$ & $\begin{array}{c}\text { For } 67 \text { days via trophic } \\
\text { transfer(Scenedesmus sp. } \rightarrow \text { D. magna } \\
\rightarrow \text { C. carassius })\end{array}$ & $\begin{array}{l}\text { NPs accumulation in the brain; } \\
\text { behavioral alterations }\end{array}$ & [55] \\
\hline Zebrafish (D. rerio) & PS NPs $(50 \mathrm{~nm})$ & $\begin{array}{l}\text { In water for } 117 \mathrm{~h} \\
\quad(1 \mu \mathrm{g} / \mathrm{mL})\end{array}$ & $\begin{array}{l}\text { Up-regulation of Gfap and } \alpha 1 \text {-tubulin; } \\
\text { decreased AChE activity; decreased } \\
\text { levels of GSH; decreased body length; } \\
\text { behavioral alterations }\end{array}$ & [56] \\
\hline Zebrafish (D. rerio) & PS NPs $(70 \mathrm{~nm})$ & $\begin{array}{c}7 \text { days }(0.5 \text { and } 1.5 \mu \mathrm{g} / \mathrm{mL}) \\
30 \text { days }(1.5 \mu \mathrm{g} / \mathrm{mL}) \\
7 \text { weeks }(5 \mu \mathrm{g} / \mathrm{mL})\end{array}$ & $\begin{array}{c}\text { NPs accumulation in the gut and brain; } \\
\text { lowered levels of AChE, dopamine, } \\
\text { melatonin, vasopressin, } \\
\text { 5-hydroxytryptophan, kisspeptin, } \\
\gamma \text {-aminobutyric acid and oxytocin; } \\
\text { behavioral alterations }\end{array}$ & [57] \\
\hline
\end{tabular}

\subsection{In Vivo Studies on Rodents}

Research into plastic toxicity in mammalian species is currently very scarce and in most part focused on the effects caused by MPs. Consequently, studies investigating nanoplastic effects in regards to the GB axis are even more lacking. In fact, a recent review by Yong et al. mentioned only 10 articles describing MNPs effects in mice, whereas another review by Prüst et al. identified only one such publication directly related to NPs neurotoxicity $[7,8]$. Nevertheless, the existing evidence allows to formulate some initial remarks and is definitely worth exploring. 
One of the few studies that examined in vivo effects of NPs in rodents was conducted by Walczak et al. as a continuation of their already mentioned in vitro experiments. The authors employed different types of $50 \mathrm{~nm}$ PS NPs, either pristine, positively or negatively charged. Plastics were administered orally to 5-week-old male Fischer rats as a single dose of $125 \mathrm{mg} / \mathrm{kg}$ bw. As subsequent analyses revealed, NPs accumulated in the intestinal wall and were further distributed to other tissues, such as kidneys, spleen, testis or heart. However, the degree of accumulation varied depending on surface modification of particles, the most pronounced effects being observed in the case of negatively charged NPs. Their calculated bioavailability was also much higher, reaching $1.5-1.7 \%$ compared to only $0.2-0.3 \%$ for pristine or positively charged particles [58]. These results clearly demonstrate the ability of NPs to affect the digestive system and other tissues, but also indicate that surface modification may significantly influence nanoplastic-induced effects in living organisms.

Limited data indicate that NPs could accumulate in mammalian organisms also in the CNS. Reineke et al. exposed male Sprague-Dawley rats orally to PS particles, 500 and $1000 \mathrm{~nm}$ in size, for $5 \mathrm{~h}$. Primary observations revealed greater amounts of $500 \mathrm{~nm}$ NPs in the stomach, whereas more $1000 \mathrm{~nm}$ MPs were found within the intestine. While MNPs of both sizes were present mainly in the liver, kidneys and lungs, the smaller ones, and only them, were also detected in the brain. An important finding was also the observation that the uptake rate was inversely correlated with particle size, suggesting that $500 \mathrm{~nm}$ NPs penetrated internal body compartments easier than larger particles [59]. Further insight into NPs distribution was provided by Fournier et al., who treated pregnant SpragueDawley rats with a single dose of $20 \mathrm{~nm}$ PS NPs via inhalation. The analysis of tissues collected from the exposed animals showed that NPs accumulated in maternal lungs, heart, spleen and uterus, but also in the placenta, fetal liver and heart. Subsequent microscopic examination revealed nanoplastic presence in lungs, kidneys and brains of fetuses. An additional ex vivo experiments on isolated placentas confirmed the results obtained in vivo. Thus, transmission of NPs to the fetus during pregnancy was proved to occur [60]. These results corroborate in vivo accumulation of NPs in the brain and highlight their potential for inducing neurodevelopmental toxicity.

While the aforementioned studies focused on NPs distribution, the subsequent experiment revealed direct impact of nanoplastic on several GI tract-related parameters. $\mathrm{Lu}$ et al. found that oral exposure of mice to $500 \mathrm{~nm}$ PS NPs and $50 \mu \mathrm{m}$ MPs resulted in a decline in body weight and a decrease in gut mucin secretion, accompanied by a lowered expression of mucin-related genes, such as Muc1 and Klf4. Additionally, numerous changes in mice intestinal microbiota were identified, in particular a significant decrease in Firmicutes bacteria. In animals treated with NPs 310 microbial operational taxonomic units (OTUs) differed from the control group, while in the MPs-exposed mice 160 OTUs were altered. As the authors concluded, MNPs of different sizes weakened the intestinal barrier and caused dysbiosis, which could eventually lead to further health problems [61]. Since microbial neuromodulatory metabolites can stimulate the vagus nerve and SCFA produced by gut bacteria are able to cross the $\mathrm{BBB}$, it can be expected that any disturbances in the gut microbiota may affect brain physiology, both indirectly and directly [31,62], which, in turn, might result in behavioral disturbances.

An explicit attempt to investigate nanoplastic neurotoxicity was made by Rafiee et al., who performed behavioral tests on adult male Wistar rats exposed orally to $38.9 \mathrm{~nm}$ pristine PS nanoparticles for 35 days. To evaluate nanoplastic influence on locomotive activity, coordination, anxiety, avoidance and spatial working memory a battery of behavioral assessments was applied, however, the authors reported no statistically significant results. Only subtle changes in the exposed rats were observed [63]. Also, Xiao et al. investigated NPs impact on rodent behavior as well as microbiota composition, intestine and brain. Similarly, the authors did not observe any behavioral alterations in mice treated orally with PS NPs (around $50 \mathrm{~nm}$ ) for 30 days. Neither inflammation nor oxidative stress parameters were affected in murine GI tract and brain, even though the intestinal wall was 
slightly damaged in the group exposed to the highest NPs concentration (10 mg/ $\mathrm{kg} \mathrm{bw})$. Additionally, microbiota composition was altered in terms of $\beta$-diversity [64].

However, more pronounced nanoplastic toxicity has been reported in a recent study by Xu et al., who administered $100 \mathrm{~nm}$ PS NPs (pristine, carboxyl- or amino-modified) to mice for 28 days by oral gavage. The exposure provoked nanoplastic accumulation in several organs, including kidneys, testis, spleen, lungs, GI tract and the brain. Histological damage to target tissues was detected, including destruction of the epithelium in the intestine as well as neuron malformation in the cerebral cortex. Changes in the brain were accompanied by an increased expression of proinflammatory TNF- $\alpha$ and interleukin 6 (IL-6). The authors performed further in vitro experiments on human Caco-2 cells to provide a mechanistic insight into processes observed in vivo. These additional analyses confirmed that PS NPs infiltrated intestinal cells and disrupted the integrity of the intestinal barrier [65]. Summarized data of in vivo studies on rodents are presented in Table 3.

Table 3. Summarized data derived from in vivo experiments on rodents regarding toxic effects of NPs related to the GB axis.

\begin{tabular}{|c|c|c|c|c|}
\hline Rodent & NPs Type and Size & Exposure & Effects Related to the GB Axis & Reference \\
\hline Fischer rat & $\begin{array}{l}\text { Pristine/positively/negatively } \\
\text { charged PS NPs (50 nm) }\end{array}$ & Single-dose orally ( $125 \mathrm{mg} / \mathrm{kg}$ bw) & NPs accumulation in the gut & [58] \\
\hline Sprague-Dawley rat & PS NPs (500 nm) & Orally for $5 \mathrm{~h}(100-125 \mathrm{mg} / \mathrm{kg} \mathrm{bw})$ & $\begin{array}{l}\text { Accumulation in the GI tract and } \\
\text { brain }\end{array}$ & [59] \\
\hline $\begin{array}{l}\text { Sprague-Dawley rat } \\
\text { (pregnant) }\end{array}$ & PS NPs (20 nm) & Single-dose inhalation $\left(2.64 \times 10^{14}\right.$ particles $)$ & NPs accumulation in fetal brain & {$[60]$} \\
\hline ICR mouse & PS NPs (500 nm) & $\begin{array}{l}\text { Orally in drinking water for } 5 \text { weeks ( } 0.1 \text { or } \\
11 \mu \mathrm{g} / \mathrm{mL})\end{array}$ & $\begin{array}{l}\text { Higher load: decreased body } \\
\text { weight; decrease in gut mucin } \\
\text { secretion; lowered expression of } \\
\text { Muc1 and Klf4; dysbiosis }\end{array}$ & [61] \\
\hline Wistar rat & PS NPs $(38.9 \mathrm{~nm})$ & Orally for 35 days $(1-10 \mathrm{mg} / \mathrm{kg}$ bw) & No changes in behavior & [63] \\
\hline C57BL/6J mice & PS NPs (around $50 \mathrm{~nm}$ ) & Orally for 30 days $(0.2-10 \mathrm{mg} / \mathrm{kg} \mathrm{bw})$ & $\begin{array}{l}\text { No changes in behavior; no } \\
\text { inflammation/oxidative stress in } \\
\text { the gut and brain; highest dose: } \\
\text { damage to the intestinal wall; } \\
\text { changes in microbiota } \\
\text { composition }\end{array}$ & [64] \\
\hline $\mathrm{BALB} / \mathrm{c}$ mice & $\begin{array}{c}\text { Pristine/carboxyl-/amino- } \\
\text { modified PS NPs } \\
(100 \mathrm{~nm})\end{array}$ & Orally for 28 days ( $1 \mathrm{mg} /$ day $)$ & $\begin{array}{l}\text { NPs accumulation in the gut and } \\
\text { brain; histological damage to the } \\
\text { gut and brain; inflammation in the } \\
\text { brain; intestinal cells penetration } \\
\text { confirmed in vitro }\end{array}$ & [65] \\
\hline
\end{tabular}

\section{Main Findings}

In spite of the long history of plastic usage and its ubiquitous presence in the environment, surprisingly little is known about the impact of synthetic materials on human health. Even though the number of studies investigating their interaction with biological systems systematically increases, the majority of questions remain vastly unexplored. One of the principal phenomena of concern in regards to plastic pollutants is their degradation into smaller forms of micro- and nanoparticles, among which especially the latter are hardly studied, although other nanomaterials have been shown to elicit a wide array of toxic effects. The data gathered so far draw a disturbing image of nanoplastic afflicting numerous species, including humans. Different exposure routes, predominantly ingestion and inhalation, further exacerbated by the trophic transfer across the food chain, make the potential health risks very plausible. The current evidence consistently points towards the ability of NPs to first accumulate in the digestive tract and later translocate to other tissues, including even the well-protected internal body compartments, such as the brain. The fact that nanoplastic can reach those two vital structures in particular suggests it may have an impact on communication pathways connecting the GI tract and the CNS.

Research regarding the influence of NPs on different components of the GB axis is scarce and only begins to scratch the surface of possible toxicity. Available data come exclusively from experiments performed on cellular cultures and animal models, therefore, any indications of potential risks for human health have to be extrapolated from these re- 
sults. In vitro studies demonstrate that nanoscale plastic particles undergo internalization, both in intestinal and cerebral cells, provoking reduced viability and oxidative damage. Moreover, under environmentally realistic conditions, they are able to adsorb other toxins, which contribute to their harmfulness. In vivo experiments on aquatic vertebrates confirm these observations, proving NPs capable of effectively distribute over the body, affecting the digestive tract and the brain. They trigger the immune response, disturb the intestinal microbiota homeostasis, induce oxidative stress and cause behavioral alterations. Finally, the few studies conducted on rodents are in line with the aforementioned research and show several alarming effects taking place upon exposure to NPs. In mammals nanoplastic accumulates in the GI tract, induces dysbiosis and undermines the intestinal barrier integrity. Furthermore, it translocates to multiple organs and passes across biological barriers, including the placental-blood barrier and the BBB, to ultimately enter the brain. Summarized effects of NPs exposure on the GB axis derived from studies presented in this review are depicted in Figure 2.

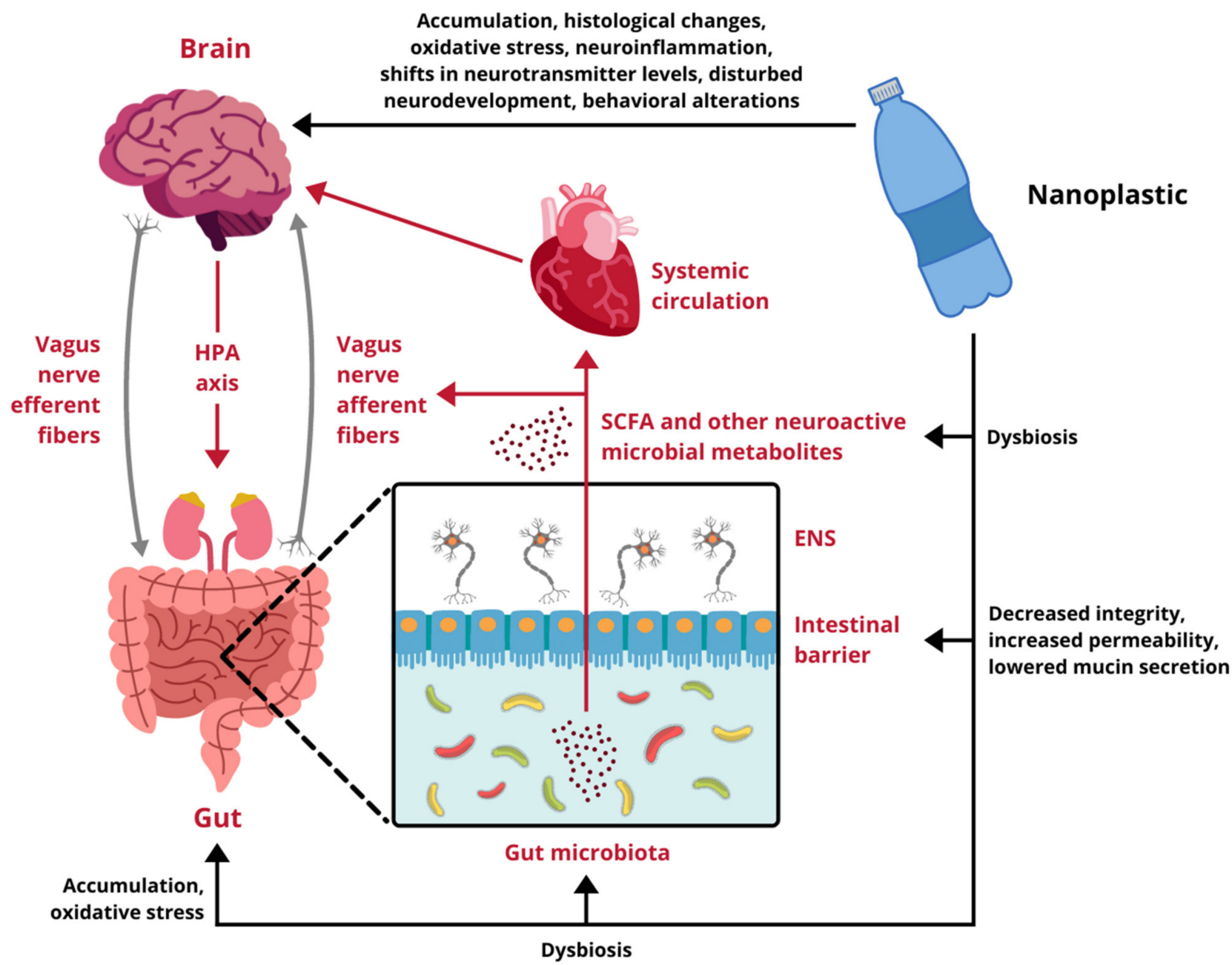

Figure 2. Impact of nanoplastic exposure on the gut-brain axis. HPA axis, hypothalamic-pituitary-adrenal axis; ENS, enteric nervous system; SCFA, short-chain fatty acids. Designed using elements by @HaticeEROL, sparklestroke, sketchify, Twemoji, Sketchify Edu, Clker-Free-Vector-Images, iconsy via Canva.com ( access date: 18 November 2021, version used Canva 2.0).

\section{Conclusions and Future Perspectives}

Although the experimental data regarding nanoplastic impact on mammalian systems are just beginning to build up, the evidence gathered up to date sheds some light on the consequences NPs exposure could have for both the GI tract and the CNS. The accumulation 
in the digestive system seems to be a factual phenomenon that might lead to dysbiosis and jeopardize the integrity of the intestinal barrier. Further biodistribution of NPs also takes place, as their presence in multiple tissues is shown consistently. One of the target organs is the brain, which suggests that nanoparticulate plastic possesses the ability to cross the BBB. Even though specific behavioral or biochemical alterations in the CNS are yet to be proven, the fact that NPs can reach cerebral compartments and affect the gut environment opens up the alarming possibility of compromised functioning of the GB axis. Toxicity determinants, such as plastic type, particle size and load, surface modification or adsorption of chemicals, as well as impact on gene expression and specific biochemical pathways involved in the gut-brain communication are examples of topics that future investigation should aim to address. Regardless of the outcomes, the widespread plastic contamination in the human environment makes preventive measures and caution highly advisable.

Author Contributions: Conceptualization, W.G. and K.D.; writing-original draft preparation, W.G. and K.D.; writing-review and editing, K.D., J.G.-O. and M.K.; visualization, W.G. funding acquisition, M.K. All authors have read and agreed to the published version of the manuscript.

Funding: The authors acknowledge the financial support of the National Science Centre, Poland through grant number 2019/35/B/NZ7/04133, 8 July 2020.

Institutional Review Board Statement: Not applicable.

Informed Consent Statement: Not applicable.

Conflicts of Interest: The authors declare no conflict of interest.

\section{References}

1. Haram, L.E.; Carlton, J.T.; Ruiz, G.M.; Maximenko, N.A. A Plasticene Lexicon. Mar. Pollut. Bull. 2020, 150, 110714. [CrossRef]

2. Alimba, C.G.; Faggio, C. Microplastics in the marine environment: Current trends in environmental pollution and mechanisms of toxicological profile. Environ. Toxicol. Pharmacol. 2019, 68, 61-74. [CrossRef]

3. Plastic Europe-Association of Plastics Manufactures. Plastics-The Facts 2020; Plastic Europe: Brussels, Belgium, 2020; Volume 1, pp. 1-64.

4. Geyer, R.; Jambeck, J.R.; Law, K.L. Production, use, and fate of all plastics ever made. Sci. Adv. 2017, 3, 25-29. [CrossRef]

5. Eriksen, M.; Lebreton, L.C.M.; Carson, H.S.; Thiel, M.; Moore, C.J.; Borerro, J.C.; Galgani, F.; Ryan, P.G.; Reisser, J. Plastic Pollution in the World's Oceans: More than 5 Trillion Plastic Pieces Weighing over 250,000 Tons Afloat at Sea. PLoS ONE 2014, 9, e111913. [CrossRef]

6. Gigault, J.; ter Halle, A.; Baudrimont, M.; Pascal, P.-Y.; Gauffre, F.; Phi, T.-L.; El Hadri, H.; Grassl, B.; Reynaud, S. Current opinion: What is a nanoplastic? Environ. Pollut. 2018, 235, 1030-1034. [CrossRef]

7. Prüst, M.; Meijer, J.; Westerink, R.H.S. The plastic brain: Neurotoxicity of micro- and nanoplastics. Part. Fibre Toxicol. 2020, 17, 24. [CrossRef]

8. Yong, C.Q.Y.; Valiyaveetill, S.; Tang, B.L. Toxicity of microplastics and nanoplastics in Mammalian systems. Int. J. Environ. Res. Public Health 2020, 17, 1509. [CrossRef]

9. Waring, R.H.; Harris, R.M.; Mitchell, S.C. Plastic contamination of the food chain: A threat to human health? Maturitas 2018, 115, 64-68. [CrossRef]

10. Blair, R.M.; Waldron, S.; Phoenix, V.; Gauchotte-Lindsay, C. Micro- and Nanoplastic Pollution of Freshwater and Wastewater Treatment Systems. Springer Sci. Rev. 2017, 5, 19-30. [CrossRef]

11. Bouwmeester, H.; Hollman, P.C.H.; Peters, R.J.B. Potential Health Impact of Environmentally Released Micro- and Nanoplastics in the Human Food Production Chain: Experiences from Nanotoxicology. Environ. Sci. Technol. 2015, 49, 8932-8947. [CrossRef]

12. Chen, C.-L. Regulation and Management of Marine Litter. Mar. Anthropog. Litter 2015, 395-428. [CrossRef]

13. Lehner, R.; Weder, C.; Petri-Fink, A.; Rothen-Rutishauser, B. Emergence of Nanoplastic in the Environment and Possible Impact on Human Health. Environ. Sci. Technol. 2019, 53, 1748-1765. [CrossRef]

14. Alvarez-Román, R.; Naik, A.; Kalia, Y.N.; Guy, R.H.; Fessi, H. Skin penetration and distribution of polymeric nanoparticles. J. Control. Release 2004, 99, 53-62. [CrossRef]

15. Hu, M.; Palić, D. Micro- and nano-plastics activation of oxidative and inflammatory adverse outcome pathways. Redox Biol. 2020, 37, 101620. [CrossRef]

16. Dris, R.; Gasperi, J.; Saad, M.; Mirande, C.; Tassin, B. Synthetic fibers in atmospheric fallout: A source of microplastics in the environment? Mar. Pollut. Bull. 2016, 104, 290-293. [CrossRef]

17. Dris, R.; Gasperi, J.; Mirande, C.; Mandin, C.; Guerrouache, M.; Langlois, V.; Tassin, B. A first overview of textile fibers, including microplastics, in indoor and outdoor environments. Environ. Pollut. 2017, 221, 453-458. [CrossRef]

18. Prata, J.C. Airborne microplastics: Consequences to human health? Environ. Pollut. 2018, 234, 115-126. [CrossRef] 
19. Hernandez, L.M.; Xu, E.G.; Larsson, H.C.E.; Tahara, R.; Maisuria, V.B.; Tufenkji, N. Plastic Teabags Release Billions of Microparticles and Nanoparticles into Tea. Environ. Sci. Technol. 2019, 53, 12300-12310. [CrossRef]

20. Danopoulos, E.; Jenner, L.C.; Twiddy, M.; Rotchell, J.M. Microplastic contamination of seafood intended for human consumption: A systematic review and meta-analysis. Environ. Health Perspect. 2020, 128, 126002. [CrossRef]

21. Rubio, L.; Marcos, R.; Hernández, A. Potential adverse health effects of ingested micro- and nanoplastics on humans. Lessons learned from in vivo and in vitro mammalian models. J. Toxicol. Environ. Health Part B Crit. Rev. 2020, 23, 51-68. [CrossRef]

22. Toussaint, B.; Raffael, B.; Angers-Loustau, A.; Gilliland, D.; Kestens, V.; Petrillo, M.; Rio-Echevarria, I.M.; Van den Eede, G. Review of micro- and nanoplastic contamination in the food chain. Food Addit. Contam. Part A 2019, 36, 639-673. [CrossRef]

23. Catarino, A.I.; Macchia, V.; Sanderson, W.G.; Thompson, R.C.; Henry, T.B. Low levels of microplastics (MP) in wild mussels indicate that MP ingestion by humans is minimal compared to exposure via household fibres fallout during a meal. Environ. Pollut. 2018, 237, 675-684. [CrossRef]

24. Cox, K.D.; Covernton, G.A.; Davies, H.L.; Dower, J.F.; Juanes, F.; Dudas, S.E. Human Consumption of Microplastics. Environ. Sci. Technol. 2019, 53, 7068-7074. [CrossRef]

25. Senathirajah, K.; Attwood, S.; Bhagwat, G.; Carbery, M.; Wilson, S.; Palanisami, T. Estimation of the mass of microplastics ingested-A pivotal first step towards human health risk assessment. J. Hazard. Mater. 2021, 404, 124004. [CrossRef]

26. Schwabl, P.; Koppel, S.; Konigshofer, P.; Bucsics, T.; Trauner, M.; Reiberger, T.; Liebmann, B. Detection of various microplastics in human stool: A prospective case series. Ann. Intern. Med. 2019, 171, 453-457. [CrossRef]

27. Ragusa, A.; Svelato, A.; Santacroce, C.; Catalano, P.; Notarstefano, V.; Carnevali, O.; Papa, F.; Rongioletti, M.C.A.; Baiocco, F.; Draghi, S.; et al. Plasticenta: First evidence of microplastics in human placenta. Environ. Int. 2021, 146, 106274. [CrossRef]

28. Carabotti, M.; Scirocco, A.; Maselli, M.A.; Severi, C. The gut-brain axis: Interactions between enteric microbiota, central and enteric nervous systems. Ann. Gastroenterol. 2015, 28, 203-209.

29. Shen, L. Functional morphology of the gastrointestinal tract. In Current Topics in Microbiology and Immunology; Springer: Berlin/Heidelberg, Germany, 2009; Volume 337, pp. 1-35. [CrossRef]

30. Deisseroth, K. A Look inside the Brain. Sci. Am. 2016, 315, 30-37. [CrossRef]

31. Cryan, J.F.; O'riordan, K.J.; Cowan, C.S.M.; Sandhu, K.V.; Bastiaanssen, T.F.S.; Boehme, M.; Codagnone, M.G.; Cussotto, S.; Fulling, C.; Golubeva, A.V.; et al. The microbiota-gut-brain axis. Physiol. Rev. 2019, 99, 1877-2013. [CrossRef]

32. Ma, Q.; Xing, C.; Long, W.; Wang, H.Y.; Liu, Q.; Wang, R.F. Impact of microbiota on central nervous system and neurological diseases: The gut-brain axis. J. Neuroinflamm. 2019, 16, 53. [CrossRef]

33. Morais, L.H.; Schreiber, H.L.; Mazmanian, S.K. The gut microbiota-brain axis in behaviour and brain disorders. Nat. Rev. Microbiol. 2021, 19, 241-255. [CrossRef]

34. Liang, S.; Wu, X.; Jin, F. Gut-brain psychology: Rethinking psychology from the microbiota-gut-brain axis. Front. Integr. Neurosci. 2018, 12, 33. [CrossRef]

35. Erny, D.; De Angelis, A.L.H.; Jaitin, D.; Wieghofer, P.; Staszewski, O.; David, E.; Keren-Shaul, H.; Mahlakoiv, T.; Jakobshagen, K.; Buch, T.; et al. Host microbiota constantly control maturation and function of microglia in the CNS. Nat. Neurosci. 2015, 18, 965-977. [CrossRef] [PubMed]

36. Carbery, M.; O'Connor, W.; Palanisami, T. Trophic transfer of microplastics and mixed contaminants in the marine food web and implications for human health. Environ. Int. 2018, 115, 400-409. [CrossRef] [PubMed]

37. Strużyńska, L.; Skalska, J. Mechanisms underlying neurotoxicity of silver nanoparticles. Adv. Exp. Med. Biol. 2018, 1048, 227-250. [CrossRef] [PubMed]

38. Teleanu, D.M.; Chircov, C.; Grumezescu, A.M.; Teleanu, R.I. Neurotoxicity of nanomaterials: An up-to-date overview. Nanomaterials 2019, 9, 96. [CrossRef]

39. Calderón-Garcidueñas, L.; Reynoso-Robles, R.; Pérez-Guillé, B.; Mukherjee, P.S.; Gónzalez-Maciel, A. Combustion-derived nanoparticles, the neuroenteric system, cervical vagus, hyperphosphorylated alpha synuclein and tau in young Mexico City residents. Environ. Res. 2017, 159, 186-201. [CrossRef]

40. Busch, M.; Bredeck, G.; Kämpfer, A.A.M.; Schins, R.P.F. Investigations of acute effects of polystyrene and polyvinyl chloride micro- and nanoplastics in an advanced in vitro triple culture model of the healthy and inflamed intestine. Environ. Res. 2021, 193, 110536. [CrossRef]

41. Domenech, J.; Hernández, A.; Rubio, L.; Marcos, R.; Cortés, C. Interactions of polystyrene nanoplastics with in vitro models of the human intestinal barrier. Arch. Toxicol. 2020, 94, 2997-3012. [CrossRef]

42. Hesler, M.; Aengenheister, L.; Ellinger, B.; Drexel, R.; Straskraba, S.; Jost, C.; Wagner, S.; Meier, F.; von Briesen, H.; Büchel, C.; et al. Multi-endpoint toxicological assessment of polystyrene nano- and microparticles in different biological models in vitro. Toxicol. In Vitro 2019, 61, 104610. [CrossRef]

43. Walczak, A.P.; Kramer, E.; Hendriksen, P.J.M.; Helsdingen, R.; Van Der Zande, M.; Rietjens, I.M.C.M.; Bouwmeester, H. In vitro gastrointestinal digestion increases the translocation of polystyrene nanoparticles in an in vitro intestinal co-culture model. Nanotoxicology 2015, 9, 886-894. [CrossRef] [PubMed]

44. Jung, B.K.; Han, S.W.; Park, S.H.; Bae, J.S.; Choi, J.; Ryu, K.Y. Neurotoxic potential of polystyrene nanoplastics in primary cells originating from mouse brain. Neurotoxicology 2020, 81, 189-196. [CrossRef] [PubMed]

45. Schirinzi, G.F.; Pérez-Pomeda, I.; Sanchís, J.; Rossini, C.; Farré, M.; Barceló, D. Cytotoxic effects of commonly used nanomaterials and microplastics on cerebral and epithelial human cells. Environ. Res. 2017, 159, 579-587. [CrossRef] 
46. Murali, K.; Kenesei, K.; Li, Y.; Demeter, K.; Környei, Z.; Madarász, E. Uptake and bio-reactivity of polystyrene nanoparticles is affected by surface modifications, ageing and LPS adsorption: In vitro studies on neural tissue cells. Nanoscale 2015, 7, 4199-4210. [CrossRef]

47. Hoelting, L.; Scheinhardt, B.; Bondarenko, O.; Schildknecht, S.; Kapitza, M.; Tanavde, V.; Tan, B.; Lee, Q.Y.; Mecking, S.; Leist, M.; et al. A 3-dimensional human embryonic stem cell (hESC)-derived model to detect developmental neurotoxicity of nanoparticles. Arch. Toxicol. 2013, 87, 721-733. [CrossRef]

48. Weston, J.N.J.; Carrillo-Barragan, P.; Linley, T.D.; Reid, W.D.K.; Jamieson, A.J. New species of Eurythenes from hadal depths of the Mariana Trench, Pacific Ocean (Crustacea: Amphipoda). Zootaxa 2020, 4748, 163-181. [CrossRef] [PubMed]

49. Veneman, W.J.; Spaink, H.P.; Brun, N.R.; Bosker, T.; Vijver, M.G. Pathway analysis of systemic transcriptome responses to injected polystyrene particles in zebrafish larvae. Aquat. Toxicol. 2017, 190, 112-120. [CrossRef]

50. Kang, H.M.; Byeon, E.; Jeong, H.; Kim, M.S.; Chen, Q.; Lee, J.S. Different effects of nano- and microplastics on oxidative status and gut microbiota in the marine medaka Oryzias melastigma. J. Hazard. Mater. 2021, 405, 124207. [CrossRef]

51. Kashiwada, S. Distribution of nanoparticles in the see-through medaka (Oryzias latipes). Environ. Health Perspect. 2006, 114, 1697-1702. [CrossRef]

52. Pitt, J.A.; Kozal, J.S.; Jayasundara, N.; Massarsky, A.; Trevisan, R.; Geitner, N.; Wiesner, M.; Levin, E.D.; Di Giulio, R.T. Uptake, tissue distribution, and toxicity of polystyrene nanoparticles in developing zebrafish (Danio rerio). Aquat. Toxicol. 2018, 194, 185-194. [CrossRef]

53. Chae, Y.; Kim, D.; Kim, S.W.; An, Y.J. Trophic transfer and individual impact of nano-sized polystyrene in a four-species freshwater food chain. Sci. Rep. 2018, 8, 284. [CrossRef]

54. Mattsson, K.; Ekvall, M.T.; Hansson, L.A.; Linse, S.; Malmendal, A.; Cedervall, T. Altered behavior, physiology, and metabolism in fish exposed to polystyrene nanoparticles. Environ. Sci. Technol. 2015, 49, 553-561. [CrossRef]

55. Mattsson, K.; Johnson, E.V.; Malmendal, A.; Linse, S.; Hansson, L.A.; Cedervall, T. Brain damage and behavioural disorders in fish induced by plastic nanoparticles delivered through the food chain. Sci. Rep. 2017, 7, 11452. [CrossRef]

56. Chen, Q.; Gundlach, M.; Yang, S.; Jiang, J.; Velki, M.; Yin, D.; Hollert, H. Quantitative investigation of the mechanisms of microplastics and nanoplastics toward zebrafish larvae locomotor activity. Sci. Total Environ. 2017, 584-585, 1022-1031. [CrossRef]

57. Sarasamma, S.; Audira, G.; Siregar, P.; Malhotra, N.; Lai, Y.H.; Liang, S.T.; Chen, J.R.; Chen, K.H.C.; Hsiao, C. Der Nanoplastics cause neurobehavioral impairments, reproductive and oxidative damages, and biomarker responses in zebrafish: Throwing up alarms of wide spread health risk of exposure. Int. J. Mol. Sci. 2020, 21, 1410. [CrossRef]

58. Walczak, A.P.; Hendriksen, P.J.M.; Woutersen, R.A.; van der Zande, M.; Undas, A.K.; Helsdingen, R.; van den Berg, H.H.J.; Rietjens, I.M.C.M.; Bouwmeester, H. Bioavailability and biodistribution of differently charged polystyrene nanoparticles upon oral exposure in rats. J. Nanopart. Res. 2015, 17, 231. [CrossRef] [PubMed]

59. Reineke, J.J.; Cho, D.Y.; Dingle, Y.T.; Morello, A.P.; Jacob, J.; Thanos, C.G.; Mathiowitz, E. Unique insights into the intestinal absorption, transit, and subsequent biodistribution of polymer-derived microspheres. Proc. Natl. Acad. Sci. USA 2013, 110, 13803-13808. [CrossRef] [PubMed]

60. Fournier, S.B.; D’Errico, J.N.; Adler, D.S.; Kollontzi, S.; Goedken, M.J.; Fabris, L.; Yurkow, E.J.; Stapleton, P.A. Nanopolystyrene translocation and fetal deposition after acute lung exposure during late-stage pregnancy. Part. Fibre Toxicol. 2020, 17, 55. [CrossRef] [PubMed]

61. Lu, L.; Wan, Z.; Luo, T.; Fu, Z.; Jin, Y. Polystyrene microplastics induce gut microbiota dysbiosis and hepatic lipid metabolism disorder in mice. Sci. Total Environ. 2018, 631-632, 449-458. [CrossRef]

62. Silva, Y.P.; Bernardi, A.; Frozza, R.L. The Role of Short-Chain Fatty Acids from Gut Microbiota in Gut-Brain Communication. Front. Endocrinol. 2020, 11, 25. [CrossRef]

63. Rafiee, M.; Dargahi, L.; Eslami, A.; Beirami, E.; Jahangiri-rad, M.; Sabour, S.; Amereh, F. Neurobehavioral assessment of rats exposed to pristine polystyrene nanoplastics upon oral exposure. Chemosphere 2018, 193, 745-753. [CrossRef] [PubMed]

64. Xiao, J.; Jiang, X.; Zhou, Y.; Sumayyah, G.; Zhou, L.; Tu, B.; Qin, Q.; Qiu, J.; Qin, X.; Zou, Z.; et al. Results of a 30-day safety assessment in young mice orally exposed to polystyrene nanoparticles. Environ. Pollut. 2021, 292, 118184. [CrossRef] [PubMed]

65. Xu, D.; Ma, Y.; Han, X.; Chen, Y. Systematic toxicity evaluation of polystyrene nanoplastics on mice and molecular mechanism investigation about their internalization into Caco-2 cells. J. Hazard. Mater. 2021, 417, 126092. [CrossRef] [PubMed] 